\title{
Re-visiting the past: How documentary practices serve as means to shape team performance at an IT help desk.
}

Ann-Charlotte Bivall and Åsa Mäkitalo

The self-archived postprint version of this journal article is available at Linköping University Institutional Repository (DiVA):

http://urn.kb.se/resolve?urn=urn:nbn:se:liu:diva-148026

N.B.: When citing this work, cite the original publication.

Bivall, A., Mäkitalo, Å., (2013), Re-visiting the past: How documentary practices serve as means to shape team performance at an IT help desk., Learning, Culture and Social Interaction, 2(3), 184-194. https://doi.org/10.1016/j.lcsi.2013.05.001

Original publication available at:

https://doi.org/10.1016/j.lcsi.2013.05.001

Copyright: Elsevier

http://www.elsevier.com/

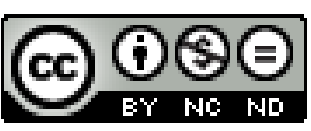




\title{
Re-visiting the past: How documentary practices serve as means to shape team performance at an IT help desk
}

\begin{abstract}
This study investigates learning at an IT help desk in a multinational production company, a work practice that has not yet been given much research attention despite its importance in many areas of society. IT help desks heavily rely on different forms of documentation for sustaining their practice and for maintaining their communication and expertise as a team. In the study, we explore how the documentation in a case management software, which is a very salient tool by means of which IT help desks perform their work, is being reused to shape the quality of the performance of the team. Through video observations of locally arranged discussions about 46 cases we analyse, in detail, the material, discursive and interactional means by which daily documentation of work is re-visited for learning purposes.
\end{abstract}

\section{Keywords}

help desk; discursive meta-activity; documentary practices; semiotic remediation; sociocultural perspective

\subsection{Introduction}

In sociocultural theory, the role of semiotic means in human activity is foundational for learning and cultural change (Vygotsky, 1997; Wertsch, 1998). Different forms of inscription are, for instance, understood as salient for coordinating social practices, for preserving information over time and for developing knowledge collectively (Mäkitalo, 2012; Säljö, 2012). The analytic interest in the mediating role of such means has gained new currency when exploring emerging cultural practices in the wake of what has been called the information age (Castells, 1996). One such practice that has not yet been given much research attention is the IT help desk - a practice 
that is ubiquitous in many people's lives, and yet still largely hidden from public view. Help desks have increasingly come to play an important role in ensuring that organizational networking systems and technologies are working properly, and that individual users are assisted when experiencing troubles with technologies. Our current knowledge, however, of how help desk teams perform their work, how they coordinate their activities and what is required of them to keep systems and networks up and running is very limited. The literature on help desks has a strong focus on productivity and has primarily dealt with issues of how to develop systems that may serve as means to store and disseminate information in the delivery of IT support. Knowledge management strategies, technical solutions to speed up work and make problem solving more efficient as well as ways of measuring the performance of employees are issues in focus in the literature (Davenport \& Klahr, 1998; Gray, 2001; Leung \& Lau, 2006; Marcella \& Middleton, 1996 Das, 2003; Gray \& Durcikova, 2006). Empirical research in this field, typically engages in the design of knowledge management systems ${ }^{1}$ (Chan, Chen, \& Geng, 2000; González, Giachetti, \& Ramirez, 2005; Heras, García-Pardo, Ramos-Garijo, Palomares, Botti, Rebollo, \& Julián, 2009; Simoudis, 1992) and studies of the implementation and use of such systems (Ackerman \& Halverson, 2004; Castellani, Grasso, O’Neill, \& Roulland, 2009; Halverson, Erickson, \& Ackerman, 2004). There are also studies that have client relations in focus since service delivery is a critical aspect of productivity (see for instance McBride, 2009; Quayle \& Durrheim, 2006). A recurrent conclusion from the studies conducted in this field is that the local structure, culture and communication of the team are critical for the efficiency of help desk practices. Since such practices

\footnotetext{
1 From a sociocultural perspective, such systems are built for managing information rather than knowledge. Issues concern the functionality of systems for information storage, retrieval and shared availability for users.
} 
are increasingly performed in shifts around the clock (to meet organizational demands in a global market), the quality and efficiency of help desk work heavily rely on the communication and collective organization of the team (Spence \& Reddy, 2012). Systems for sharing solutions as well as possibilities of documenting steps taken in ongoing problem solving processes are clearly critical elements for such practices to be able to function smoothly. The focus on knowledge management systems within this field thus seems to echo these concerns. Still, little is known about the ways team members collaborate and communicate in such local practices and their uses of, and reliance on, particular kinds of documentation for the maintenance of help desk practices. One question that has not yet received much attention is how such teams draw on knowledge management systems to perform their tasks and enhance their work.

The present study is part of a research project ${ }^{2}$ where this general question has been explored in a help desk practice at a multinational production company. At this particular help desk several strategies in the social organization of knowing were identified; overlapping activities, redundancy of information and a future orientation to potential problems and alternative scenarios enabled the team to maintain the continuity of work (Eklund, Mäkitalo \& Säljö, 2010). A number of activities were identified as critical for achieving continuity and they relied on documentation of everyday work, or what we will refer to as documentary practices (i.e. documentation for record keeping and reporting). In the daily activity of problem solving, for instance, a case management software was used for the documentation of every step

2 This project has been funded by the Swedish Research Council. 
taken in such work. By enabling recapitulation of the actions taken up to the point in question, through the written media, important premises for pursuing the problem solving process over shifts were settled. The second documentary practice that we identified was the use of a shift report that served the particular purpose of organizing and securing shift handovers. Entries on the shift report covered other issues that were important to initiate and follow up and they were checked in a systematic manner. The idea was to report what had happened during earlier shifts regarding issues of network maintenance and service along with advice received from so called back offices with specific expertise in systems and applications (Eklund et al, 2010). The third documentary practice that team members engaged in was provided by means of a web hotel where they shared some information and solutions to technical problems. So, while the former two documentary practices supported the ongoing organization of everyday work, the latter could be seen as an attempt to build up resources for a shared body of professional knowledge, potentially useful across cases and local settings. Teamwork in this setting was accordingly pursued through a set of related social activities that relied on documentary practices. Team members were pursuing work by invoking and drawing on the past actions and experiences of the team in appropriate and skilled manners (Eklund et al, 2010).

During our empirical studies we noted that the documentation that was saved in the case management system also served as the basis for arranging a separate and highly reflexive communicative activity ${ }^{3}$. The local quality team (QT) reviewed the case documentation in systematic ways and re-used it in a specific activity they arranged

\footnotetext{
3 It was highly reflexive in the sense that it was arranged to revisit and review past actions through the available documentation, but also to discuss the quality of that documentation to communicate actions taken.
} 
for learning purposes which locally was referred to as the Case studio. This kind of discursive meta-activities are of general interest for sociocultural studies of learning and interaction, since they seem to become more salient in a society where actions performed are digitally stored and easily retrieved and shared with others ${ }^{4}$. For our project, this activity also provided an opportunity to learn more about the IT help desk as a practice and how it needs to be organized to meet current expectations and demands. Our aim in this study, is to describe recurrent features of this discursive meta-activity and to analyse the use of the case documentation in terms of the analytic notion of semiotic remediation (see below), i.e. in what ways such daily inscriptions come to serve as a means for learning. Empirically, we were guided by the following research questions:

- How is this discursive meta-activity organized?

- How is the case documentation used to mediate issues of concern?

- How is the discussion of past events used to shape future teamwork?

However, before attending to our empirical study, we would like to account for our theoretical perspective by drawing on relevant analytical insights from research with an interest in communication, material-semiotic means and remediation in collaborative activities.

\subsection{Semiotic remediation in collaborative activities}

In line with a sociocultural perspective, the documentary practices at the IT help desk,

4 See for instance the discussion on the textualisation of work in Scheeres (2007); or on electronic archives as devices for remembering in Brown, Middleton \& Lightfoot (2001). 
are understood as externalizations of human knowing (Säljö, 2010). Such documentation constitutes current forms of cultural inscription, generated from a pragmatic need to organize work collectively over time, to be able to recapitulate earlier action and account for what are considered relevant concerns in order to maintain the joint activity for the future (Mäkitalo, 2012). The notion of semiotic remediation that frames our analysis in this article refers to "the diverse ways that humans' and nonhumans' semiotic performances are re-represented and reused across modes, media, and chains of activity" (Prior, Hengst, Roozen \& Shipka, 2006, p. 733). In our case, such semiotic remediation concerns how the case documentation is re-presented and reused as a constitutive element in the discursive meta-activity.

As resources for communication and action, semiotic means necessarily take on some material form (Wertsch, 1998). Certain distinctions and categories for organizing digital information are for instance necessary to be able to create any kind of software, database or archive. Such distinctions will generate certain premises for people's interaction with such means and become salient as affordances and constraints for action when in use. As Hutchins (1995) noted in his study of distributed cognition in a cockpit, interaction, gestures and technological devices together formed a redundant information processing system. The material arrangement of the representational tools had some inherent qualities that were useful at specific moments, allowing coordination and providing "multiple opportunities for consistency checks in the system of distributed representation." (Hutchins, 1995, p. 277). The system, as a whole, was also a system capable of remembering through "the creation, inside the system, of a representational state that is then saved and used to organize subsequent activities." (Hutchins, 1995, p. 279). This allowed the 
participants to shape future activities and organize the system of distributed cognition. Accordingly, the inherent material qualities of mediating tools, particularly as regards how certain phenomena (for instance speed and height of the aircraft) or processes (actions taken in the problem-solving process), are re-presented, are crucial to attend to.

A second relevant example of what we refer to as semiotic remediation is reported in Button and Sharrock's (2000) ethnomethodological study of the use of documentation in software design meetings. The problem-solving process these engineers were engaged in was based on a 'fault report form'. Such reports, automatically generated by the malfunctioning systems, were not satisfactory when it comes to grasping ideas of 'what happened" and the engineers accordingly needed to re-read this report to be able to use it intelligibly. The engineers, for instance, highlighted time as indicative of the successive development of events when working on sequencing the information into a temporal order. From this temporal organization, the engineers 'read in' facts and conjectures, transforming the temporal history "into a causally textured account of the problematic operation of the machine" (Button \& Sharrock, 2000, p. 61). The close analysis of the interaction resulted in the disclosure of an interactional structure where it was shown how information in the documentation subsequently was transformed into forthcoming actions. The implications of the study suggest we should attend to the construction of events where 'reading-in' is a necessary step to make sense of an earlier course of events and identify possible sources of trouble. 
The last example of semiotic remediation that is relevant to our present study is to be found in Orr's (1996) ethnographic study of support technicians. An interesting aspect of remediation in this study is how stories were tailored to re-present experiences of earlier actions and events to fit the occasion in which they were told. Orr (1996) noticed that stories were given function and purpose and thus could be described as having a salient function for both learning and remembering what is relevant when pursuing the activities at hand. Orr claims that "it is crucial to note that stories do more than celebrate the job; they are part of the job." (Orr, 1996, p. 143). Through stories, earlier experiences are actualised and often animated, they are given a dramaturgical format and a point to which the listeners are subjected. As a form of oral re-enactment of human experience, narratives are historically one of the most established means of semiotic remediation for learning purposes.

The way the documentation is brought into the situation as an object for intervening in current help desk practices is worth exploring in terms of semiotic remediation, since everyday documentation of people's actions are increasingly used reflexively in contemporary work (Mäkitalo, 2012). As has already been stated, our aim in this study is to describe recurrent features of the Case studio as a discursive meta-activity and analyse the case documentation in terms of semiotic remediation, i.e. in what ways these inscriptions of everyday conduct come to serve as a means for learning. In the following, we will give a short introduction to the help desk and the work of the team before the results of our analysis are presented.

\subsection{Data production and analysis}


The data we draw on in this study consist of video recordings of five Case studios. We used two cameras where one captured the participants and the other the screen showing the case documentation. In figures, the data material amounts to 8,5 hours of video observation, transcribed verbatim ${ }^{5}$, covering a total of 46 cases. The first part of the analysis was performed across the 46 cases to be able to establish how this activity was both formed and maintained as a sequentially organized discursive event (Linell, 2009). In this analysis, we found a recurring pattern of sequentially ordered phases (Linell, 2009, p. 204). When presenting the results of our analyses, the first part describes the Case studio as constituted by such recurrent phases. The second part of our analytical work then scrutinizes in detail the interactional work of making sense of one case. This case was selected from the collection of cases as it is readily comprehensible to a reader without specialized knowledge in technical terminology and because it was deemed to constitute a typical case in our material. We will give a detailed account of this case with the aim to illuminate the characteristic ways through which the case documentation is remediated to fit the purposes of this discursive meta-activity. It thus serves the motive of illuminating in detail how documented actions of earlier conduct are re-presented and reused for learning purposes.

\subsection{The Global Help Desk and the Case Studio}

The Global Help Desk (GHD) we studied consisted of about fifteen support engineers within an IT department of a multinational production corporation. They constituted a so called offline help desk, which in its simplest term implies dealing with more advanced problems than staff at frontline help desks (i.e. clients' first point 
of contact $)^{6}$. GHD's responsibilities included maintenance and support of appointed areas of locally developed software and network systems. The help desk covered a global market of clients, resulting in shift work 24/7 to allow for time differences. The shifts were based on a rotation of individuals which created changeable shift constellations where everyone got to work with everyone on weekly basis. Generally, GHD was expected to achieve the shortest turnaround possible of cases to avoid violation of service agreements or dissatisfied clients negatively affecting the reputation of the IT department. The organizational solution for complying with such expectations, and a necessity because of the changing shift arrangement, was collaboration and co-ordination of the support engineers' work so that no one person owned or controlled individual objects of work (Button \& Sharrock, 1998). Generally, this meant that team members needed to communicate actions taken to advance the problem-solving, know where to find appropriate information and continuously share the essentials of the object of work with the rest of the team to anticipate and prepare for future system failure.

Clients' requests for help primarily showed up in writing on the computer screens through the case management software. As we already have mentioned, this software filled two important functions in everyday work at the empirical site we studied. It was used as a resource for making notes on case progress and activities. Such notes included progressive steps in diagnosis and repair, phone calls with clients, pasted email communication and other information. The main idea (and their ideal) was that everything concerning a case should be documented in order for other members of the

6 For explanations of help desk organizational structures, see El Sawy \& Bowles, 1997; Kajko-Mattsson, 2003; Leung \& Lau, 2007. 
team to recapitulate previous actions and continue the problem solving at the last point of entry. In the Case studio, however, this case documentation was taken out of its original context and was used as a means of discussing the quality of work. Case studios were arranged two to three times per year and was distinguished from ordinary work by its physical placement in the conference room, which otherwise rarely was used. The QT, that arranged this activity, consisted of experienced previous team members who now was in charge of evaluation and quality assurance of the support work. Part of their preparatory work for the Case studio was to go through the vast amount of documented cases, to analyze work activities and evaluate the performances as having been more or less productive. In the preparation the QT focussed on points of improvement as well as accreditations of good practice. Having decided on general themes, the QT selected cases to serve as examples and ground for collective discussions of good as well as improvable ways of performing work activities. There were particular ways of setting up the room. The larger part of the conference rooms used were taken up by a conference table, around which the participants sat, facing a projection screen. The leader, a QT member, was placed in front of the table to the left of the projection screen, facing both the participants and the screen. Before the Case studio, the case documentation had been printed from the case management software and copied onto transparencies for overhead projectors. Transparencies were used because of their particular affordances. It was time efficient to print transparencies from the case documentation in which the entries were already organized chronologically. The transparencies also allowed the leader to quickly cross out the names of the engineers involved and particular entries could also easily and flexibly be covered or uncovered during the discussion. The QT accordingly anonymized the material, discretely avoiding individuals in the team to be pointed 
out. The attention was instead directed towards the team's performance as a collective.

\subsection{The discursive organization of the Case studios}

As a result of our analyses of the case studios, we discovered that the talk about cases shared features throughout our data material in terms of a sequentially organized phase structure (Linell, 2009, p. 204), and that the prepared case documentation seemed to constitute an "institutionalized template for social action" (Orlikowski \& Yates, 1994, p. 542). Below we outline the discursive pattern and sequentiality which, we wish to emphasise, is based on an analysis across the 46 video recorded cases. The five phases we recognised as recurring and distinctive features of the discursive activity were the following ${ }^{7}$ :

Categorising the case

Articulation of past events

Pointing out the object of talk

Articulation of the general point

Making sense of and accounting for previous actions

\section{Phase one: Categorising the case}

The first phase served as an opening. The leader, doing most of the talking in this part, marked the beginning of a case and called upon the engineers' attention through an opening phrase that categorised the case in intelligible ways to the engineers. This

\footnotetext{
7 This pattern is based on problematic cases that dominated the data material in number and in time discussed. Good examples were constituted by phases one, two and four with a distinctive difference in the fourth phase; when good cases were narrated the leader was not provided with, nor did she ask for, contributions from the engineers. Overall, less interaction seemed necessary when good examples were presented.
} 
short phase, consisting of one or just a few turns, prepared the engineers in two ways: a) if they were to encounter a problematic or a well-performed case, and b) which technical systems were involved. For example, in one case the leader began with: "let's see, then we have a server problem, or server case". This kind of phrase had the same function regardless of the status of the case: to direct the attention and expectation of the engineers. The documentation sheets were typically then placed on the overhead projector with the text still hidden.

\section{Phase two: Articulation of past events}

The second phase served the purpose of contextualising the issue to be discussed. In this phase a sequence of events was presented step by step by means of the entries made in the case documentation. The engineers followed the leader's visual display of these events on the projection screen, as the leader uncovered them, entry by entry at the same time as s/he orally shared the text with the team. Still, the leader is taking up most of the conversation space. Even though the text was sometimes read word by word, the leader dramatised the sequence of events by verbally emphasising certain but not other parts of the content. The result of this was that certain actions taken in the past were made salient to the engineers. At the same time, the events were sequenced in temporal order; the engineers had a full view of the uncovered text and were seen to read on the projector screen. The oral re-enactment of the text accordingly seemed to form an emplotment; the leader used the sequenced entries in text to form an account, which took the form of a narrative. In this phase, thus, the sequencing of time as narrated, was used to retrospectively suggest how actions and events were connected, i.e. a description of what happened during the course of 
events, which preceded the particular instance to which participants' attention was to be directed.

\section{Phase three: Pointing out the object of talk}

The third phase served to highlight the issue to be addressed. In each case presentation, there was a point at which the leader stopped the review. Up to that point the engineers had followed the documented events and the narration of them simultaneously. By means of questions such as 'What would be your next step here?' or 'How was it possible to know that...?', the leader used the documentation to arrive at a point where the engineers responded as if they themselves had been in the situation and would have to act on the information given. The engineers were now more engaged in the conversation. Their answers and reactions were mostly concrete and specifically tied to the case presented, as if they would indeed take the next step in the problem-solving procedure. At this point, the engineers in different ways had usually already shown that they were aware of the exceptional and problematic nature of the case. If a case had been selected on the basis that it was a good case, the leader did not stop to ask questions in this manner. In such cases, the leader would simply continue reviewing the events onto the next phase where the case was to be constituted as a model case, worthy of imitation.

\section{Phase four: Articulation of the general point}

The fourth phase served to formulate and, hence, jointly make articulated sense of the issue addressed. During this phase it became clear that "the meaning of the text is no longer reducible to the sum of the chronicled events." (Ryan, 2006, p. 81). The leader would, for example, uncover the text but quietly let the engineers read the passage. 
The text as such was accordingly to be used and interpreted by the engineers (rather than having the leader tell the story). The question used in phase three seemed to function as guidance of what to discover, as the leader refrained from providing any explanation. In the cases analysed, there was no need for further explanation of the intention with the selected case at this stage. Using the engineers' answers and comments, the case was instead taken up and formulated by the leader as an example of a general issue. Accordingly, during this phase, the function of the narrative was transformed and expanded on. From being a report of events, it developed a potential of including a sense morale since the actions performed by the team carried exemplary value. The leader pointed out how work was expected to, or ideally could, be performed.

\section{Phase five: Making sense of and accounting for previous actions}

The fifth phase served to make sense of the exceptional events or actions, that were considered problematic in nature. The engineers never questioned the general point of such cases per se, but as accountable members of the team they did respond to how cases had been followed through. This is also the phase in which the engineers gained greater speaking space than previously. The engineers themselves pointed to critical aspects of work performance observed in the presentation of the events. A collective sense-making process took place during this phase where accounts of specific actions were given and discussed. Sometimes such discussions resulted in normative generalisations of what they as a team regarded as a preferred conduct. The leader, showing the settlement of the case on the screen, in most cases reminded the participants of the general point arrived at before concluding each case presentation. 
In the following presentation of our continued analysis, we will illustrate how this general pattern was achieved interactionally.

\section{0 Making a lesson out of a case}

We will now move on to a closer analysis of the interactional work of turning a case into an example and a lesson to be learned. In this case, the problem as pointed out by the leader was negligence in using available information in the problem-solving process that lead to a mix-up of information that, possibly, could have caused serious trouble for the client, and, subsequently, for the team in terms of failure in their commitments. The problem pointed out by the leader was that the user's problem description had not been properly read, and that this negligence in reading carefully almost resulted in a faulty action with potentially serious consequences. By using this case as a concrete and common point of departure of talk, the leader points out and reinforces general guidelines about careful reading. In this manner, she reminds the team of the importance of being attentive to details when dealing with client queries.

The analyzed case documentation concerned an assignment formulated in an e-mail, in which the help desk team was asked to remove two user identities from a specified system. This gave rise to a series of actions. To begin with, the support engineer who took the case reformulated it into a request and sent it to the team in charge of this (locally referred to as STT), thus following the correct routine. In the formulation of this request, however, the support engineer asked for the deletion of the e-mail sender's user identity, rather than the two user identities specified in it. The STT engineer receiving the request, found the request ambiguous and wrote back asking GHD for clarification which lead to the discovery of the mistake. All of this 
communication between teams was in written form and done in the digital case management system. We will now turn to the details of how the documentation of this case was used as material-semiotic means to mediate issues of team concern, and how discussions of past events were used in the shaping of shared prospective team practice.

\subsection{Narration and negotiation}

\section{Excerpt 1}

\begin{tabular}{|l|l|l|}
\hline 1 & Leader & this is only to show how things can go wrong \\
\hline & Ida & $m$
\end{tabular}

The objective of the Case studio as an arranged activity is visible already in the leader's opening phrase: "this is only to show how things can go wrong". This opening makes clear that the expectations in this particular case should be focused on a problem issue and that it is a matter of principle. The general formulation is also a way of avoiding pointing out individuals as being personally accountable for the mistake, which is characteristic of this activity. This is further visible in how the support engineers' names are omitted and replaced with the collective GHD (e.g. entry 2 below). As the leader verbally initiates the case, she simultaneously puts the documentation on the overhead projector, keeps it hidden for a few seconds and then uncovers the first two text entries of the case (E1 and E2) as she continues talking about the case.

Entry $1^{8}(E 1)$

8 The printout of the text entries as retrieved from the case management system includes text content (the message) and header information (such as date, time, sender and receiver). The latter has been omitted here. The text content is however replicating the original case documentation but made confidential by the authors for ethical reasons. Thus, Entry 1 appeared as 


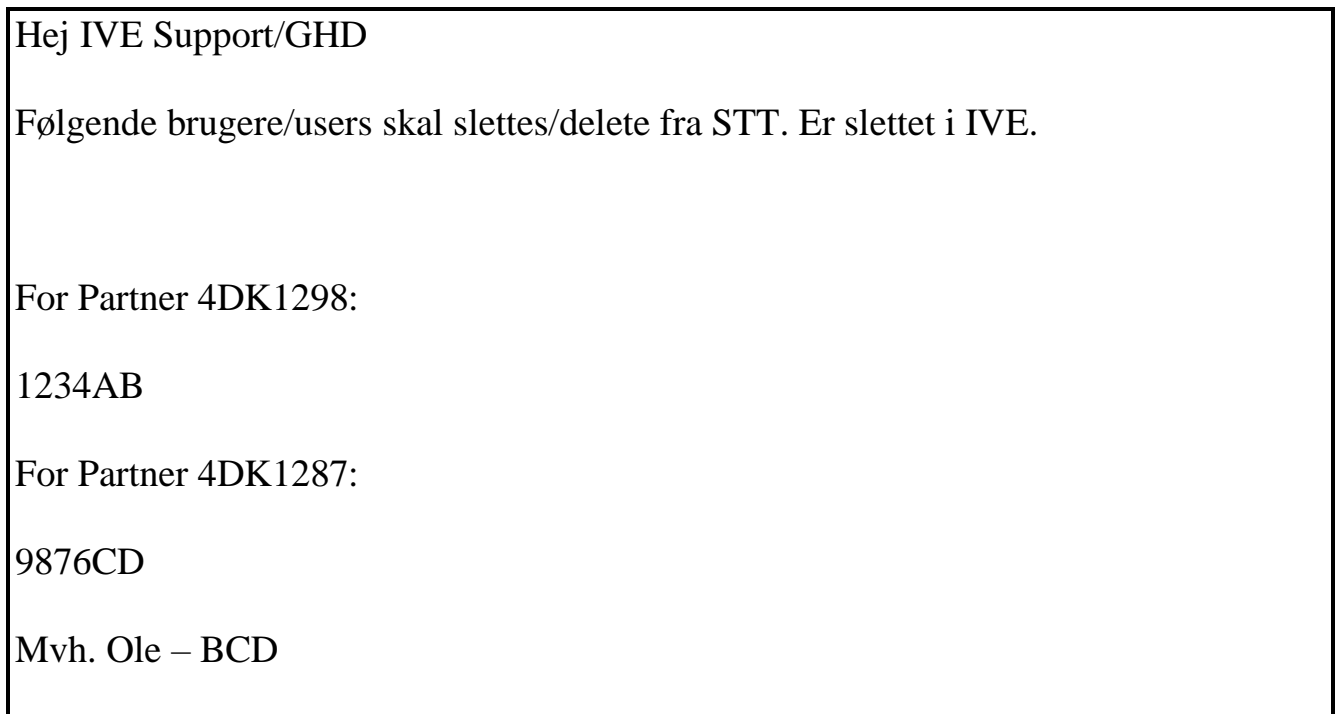

Entry 2 (E2)

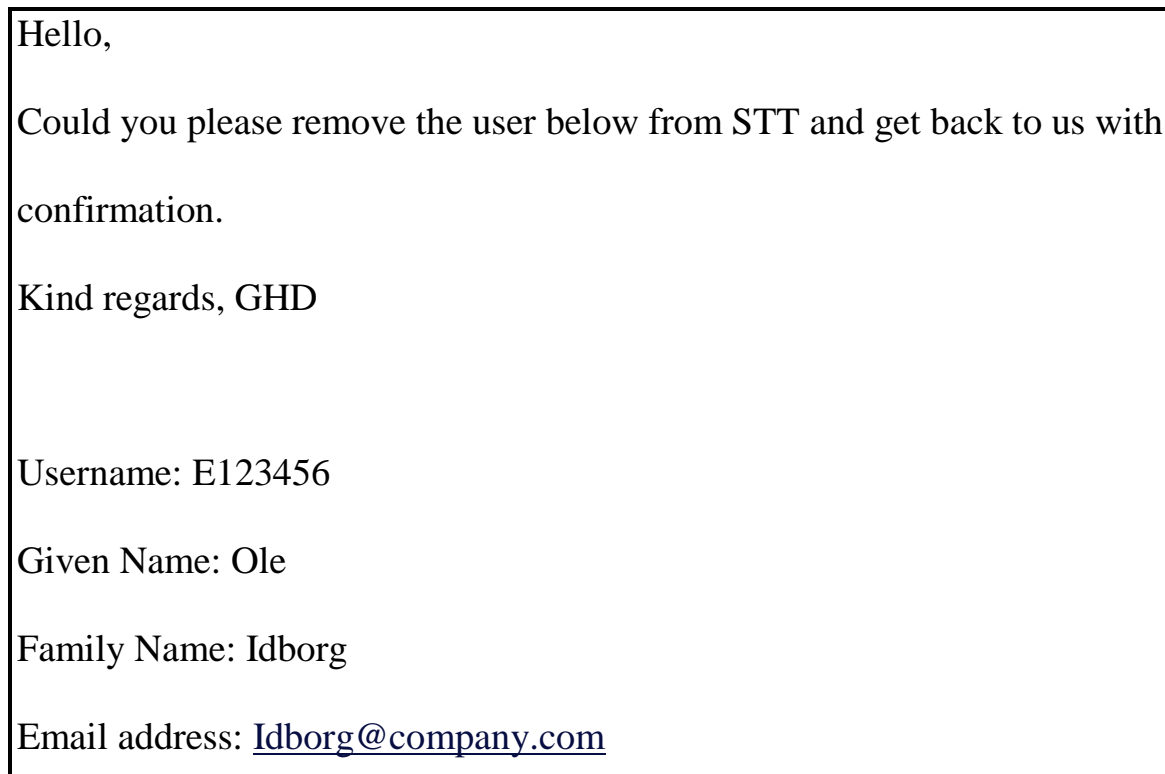

\section{Excerpt 2}

above mixing Danish with English. This does not correspond with accepted ways of communicating in this corporation but in the three Nordic countries Sweden, Denmark and Norway it is possible to speak the native language and make oneself understood. The conventional language of communication in this organization is English which the rest of the entries comply with. 


\begin{tabular}{|c|c|c|}
\hline 3 & Leader & $\begin{array}{l}\text { euh Ole Idborg (.) from Denmark (.) has written } \\
\text { to us here and wants us to delete users from STT } \\
\text { and its one two three four a b and nine eight } \\
\text { seven six c d that are to be deleted then GHD } \\
\text { sent it off to STT support (.) and he asks ehh he } \\
\text { or she from [from GHD }\end{array}$ \\
\hline 4 & Erik & {$[$ exact $l y$} \\
\hline 5 & Leader & from GHD that we should delete Ole Idborg \\
\hline 6 & Rune & ((heavy exhalation)) \\
\hline 7 & Ida & you're kidding= \\
\hline 8 & Leader & $=$ from STT \\
\hline
\end{tabular}

The leader's way of retelling this case is a narrative mix of reading the text word by word and highlighting or omitting words. The header information is reformulated into explanatory notes: "then GHD sent it off to STT support" (turn 3), linking text content with actions performed. The documentation is brought to life and is animated as a scenario of the past, one that is collaboratively relived in the present. Erik, being also responsible for quality and familiar with the case helps co-producing the incident as a failure event (turn 4) in an illustrative tone of voice. The engineers' reactions to this (turns 6 and 7) forcefully signal that they notice something that deviates from the expected. While following the engineers' reactions the leader completes the conjoint activity of re-creating previous events, as she ends her narrative with "=from STT" (turn 8). The creation of a story, supported by the content and structure of the documentation, seems to be enough to make the point clear to the team. The articulation of a question to highlight the issue, as described in phase three (see section 5.0), is absent in this example. As such questions typically 
serve the function of orienting participants' attention by zooming in on a key aspect, it can be assumed to be unnecessary as this has already been achieved. The engineers clearly reacted in relevant ways to the critical instance, when the issue was revealed. The fact that the parties are aligned in their normative expectations as regards the situation described is also noticeable because of the absence of explanations. There is, we argue, a notable transparency of the relevance of taking up this specific case as an example. However, this discursive meta-activity is not only about making a problem visible to the participants, it calls for the leader to comment on it.

\section{Excerpt 3}

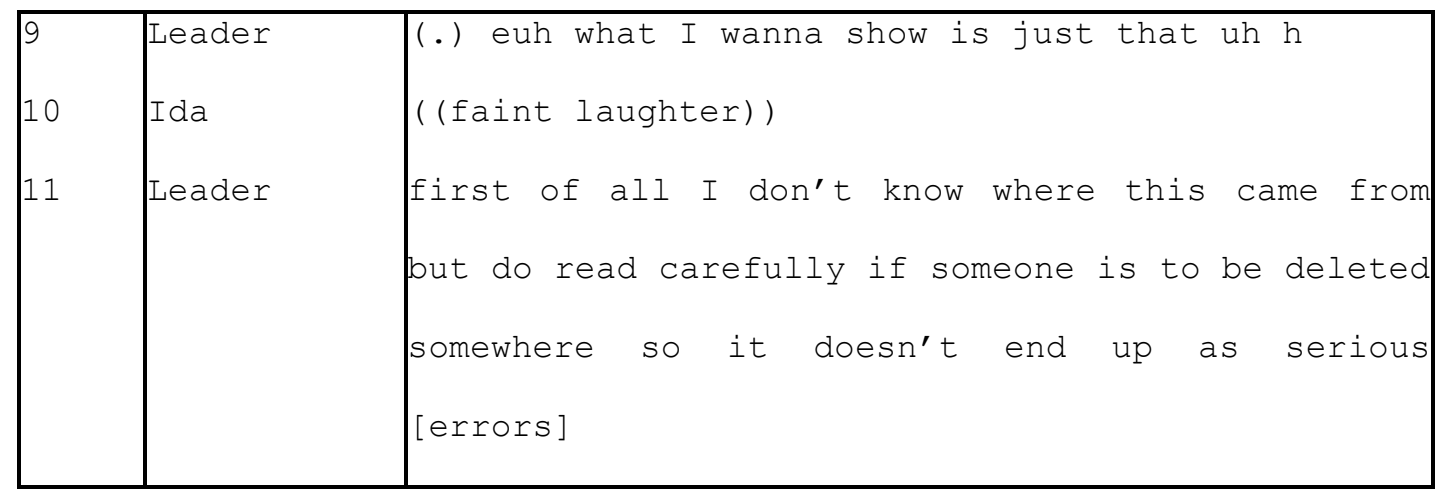

As the leader moves on (turn 9), she steps out of the narrative of events, to metacommunicate the lesson to be learned. As she says: "euh what I wanna show is just that uh $h^{\prime \prime}$ there is both hesitation and laughter in her voice accompanied by a smile, which mitigates the issue yet it is brought up. In this sense, the utterance can be understood as dispreferred, and maybe also an implicit excuse for bringing up a case for discussion that is, most probably, already too obvious to the engineers. Ida responds with laughter (turn 10), making it reasonable for the leader to continue with an appeal to work conduct: "do read carefully if someone is to be 
deleted" (turn 11). This is a forceful way of making a point, as it is tied to the specific case, one that the engineers responded to strongly. From an analytical viewpoint, the discursive meta-activity in this way produces an interpretive theme that subsumes and creates meaning from the sequenced events.

\section{Excerpt 4}

\begin{tabular}{|c|c|c|}
\hline 12 & Ida & $\begin{aligned} \text { [ah but] go } & {[\text { did we paste it }=} \\
& {[\text { (Ole yeah but) }}\end{aligned}$ \\
\hline 14 & Leader & $=[$ yeah like that $]$ \\
\hline 15 & Ida & [Ole there] \\
\hline 16 & Leader & we sent it [and this is how it ended up] \\
\hline 17 & Ivan & [someone read in the template on ( )] \\
\hline 18 & Leader & $\begin{array}{l}\text { that we shall see (.) uh Elin responded down here } \\
\text { from uh from STT support that uh uh this user has } \\
\text { both IVE and ISL system users authorities are } \\
\text { both to be deleted and then we had to correct } \\
\text { this 'oops it's pure luck you sent this mail } \\
\text { because he's not the one to be deleted its one } \\
\text { two three four a b, nine eight seven six c d' and } \\
\text { then she deleted them and we send it to him }\end{array}$ \\
\hline 19 & Ida & ooh \\
\hline 20 & Leader & $\begin{array}{l}\text { but, precisely, be careful when reading } \\
\text { especially if someone is to be deleted be careful } \\
\text { to read accurately (.) and if you're uncertain } \\
\text { about what it says or you don't understand please } \\
\text { ask one time too many then }\end{array}$ \\
\hline
\end{tabular}


So far, the verbal re-enactment of the text entries has turned into a plot and a story of a failure with possibly serious consequences. The rationale and point of showing this case has accordingly been explicated. Almost simultaneously, as the point is made clear, the engineers collectively start to unravel the situation. However, as we pointed out in section 5.0, the pattern of this activity calls for the cases to be fully displayed and concluded before continuing. The leader accordingly does not respond to the engineers' uptakes but moves on to close the presentation of past events: "we sent it and this is how it ended up" (turn 16). She continues to hold the floor in the next turn, "that we shall see" (turn 18), while uncovering further text (see E3 and $\mathrm{E} 4$ below), signalling to the engineers an intention to continue narrating the case.

Entry $3($ E3)
Hello,
This user has access to both IVE user and ISL systems users, is it both groups that should be deleted, and the id?
Best Regards, Elin

Entry $4(E 4)$

Hello Elin,
We are sorry for the inconvenience [sic], but the user IDs that should be removed are
NOT E123456 they are:
$1234 \mathrm{AB}$ and $9876 \mathrm{CD}$
We are grateful for your question that made us aware that it was wrong user ID,
THANK's!! Please inform us after the above user IDs have been removed.


Best Regards, GHD

In the middle of turn 18 , the leader give voice to the author of the case documentation: "oops it's pure luck you sent this mail because he's not the one to be deleted its one two three four a b, nine eight seven $\operatorname{six} c d^{\prime \prime}$ rather than reading the entry in E4. With a mix of animating the text and adding cues like 'oops' and 'pure luck' the leader points out the actions of the team member as being exceptional and accidental ${ }^{9}$. That luck is pointed out as a factor of success, rather than meticulous teamwork, suggests instability in the collaborative effort of maintaining quality in the delivery of services. The leader thus calls for attentiveness and for collaboration to achieve high-quality team performance; such instability is not accepted in this environment.

Now, the full story as found in the documentation has been re-told. The leader reinforces (turn 20) the normative expectations, addressing the team as a collective; it is expected they are meticulous and one hundred per cent accurate in cases where user identities are to be deleted. Next, she also suggests how this can be accomplished by re-mentioning the team as a resource to be used.

\section{Excerpt 5}

9 The initial 'oops' is in the framework of conversation analysis analysed as a doer's trouble-marker (Schegloff, 2005), 


\begin{tabular}{|c|c|c|}
\hline 21 & Ida & $\begin{array}{l}\text { well, but I do think Danish as a language is } \\
\text { guite difficult= }\end{array}$ \\
\hline 22 & Leader & $\begin{array}{l}\text { =precisely, write if you find it difficult or } \\
\text { double check write in English and ask him }\end{array}$ \\
\hline 23 & Erik & or ask a colleague \\
\hline 24 & Leader & $\begin{array}{l}\text { or ask a colleague who finds Danish easier or } \\
\text { something I just wanted to show how wrong things } \\
\text { can get }\end{array}$ \\
\hline
\end{tabular}

With reference to her own experience, Ida seems to provide an interpretation of the faulty action as possible due to language deficiency: "well, but I do think Danish as a language is quite difficult" (turn 21). This utterance addresses the issue of individual versus team orientation. It can be analysed as an account that situates the speaker in the position of being the doer of the faulty action. But since we know this is not the case here, the utterance can instead be understood as a hypothetical account or reflection to make sense of the unexpected. The utterance is not, however, taken as an acceptable account in this discursive meta-activity. The leader instead uses it as an example of a situation in which team members should always be attentive and make sure they know what is communicated ("=precisely, write if you find it difficult or double check write in English and ask him"). In this way, the situated ways of being and staying knowledgeable, which are expected in this setting, are displayed and a code of preferred conduct is articulated, addressing all the engineers by using a generic 'you'. Erik contributes to this display of possible actions and brings in the team as a possible and available resource (turn 23). The common interpretation of the problem and teamwork as a 
shared practice is stressed again, and the leader concludes that the importance of attending to these matters was the point to be made here (turn 24).

\subsection{Acting as a team - accounts of a faulty action}

In the preceding part, we showed how failures and normative expectations were verbalised and made sense of. As the interaction continues, Ida's delivery of a hypothetical account seemed to serve as a starting point to the fifth phase of the Case studio: to continue elaborating on how and why the faulty action did occur. At this stage, the engineers demand a review of the case and instantly follow the leader's request by paying detailed attention to the original case request.

\section{Excerpt 6}

\begin{tabular}{|c|c|c|}
\hline 25 & Rune & $\begin{array}{l}\text { how did it start you said the case can I just see } \\
\text { ( ) }\end{array}$ \\
\hline 26 & Erik & Ole sent in a case to delete \\
\hline 27 & Ida & ( ) users \\
\hline 28 & Rune & yea: yea: \\
\hline 29 & Ida & but he actually did write "users" \\
\hline 30 & Rune & but it's in \\
\hline 31 & Leader & ( ) delete from STT so it shouldn't be \\
\hline 32 & Rune & $\begin{array}{l}\text { but its impossible to get it wrong even though it } \\
\text { is in Danish }\end{array}$ \\
\hline 33 & Ida & $\begin{array}{l}\text { yea 'cause it says ( ) below so it's quite } \\
\text { obvious even if it is in Danish }\end{array}$ \\
\hline 34 & Leader & $\begin{array}{l}\text { lucky I don't recognise the case } \\
((\text { laughs)) it wasn't you Rune }\end{array}$ \\
\hline
\end{tabular}


Rune asks for visual access to the text, as a way of revisiting and assessing the case documentation in the light of the just narrated events. As Erik responds to the request, Rune and Ida direct their gazes towards the text on the projection screen and it can be assumed Ida reads the text as she fills in "users" (turn 27). While reading at this detailed level, Ida (in turn 29) refers to the original request written in Danish emphasising that the word 'users' was in English and in the plural. She thus demonstrates that by reading carefully it should have been obvious that there were two identities to be deleted and that the support engineer who wrote to STT (see E2) ought to have noted that two rather than one user identity were to be deleted. The message is, in her view, fully comprehensible and the mistake could have been avoided. Rune (in turn 32) also disqualifies language deficiency as a reasonable cause of the misreading. Ida reinforces this by emphasising the visibility of the task (the identities concerned were stated below the demand for removal almost as bullet points in the original message), and this, Ida says, should be obvious regardless of language (turn 33). The engineers in this manner co-produce a description, by acknowledging and orienting to the text and each other as a team. It seems that the collective account permit the team to a shared reconstruction of events, where the joint narrative provide the engineers the resources for reciprocal understanding and interpretation of the cause of the problem. When a gap between action and expectation turns into a failure where the team do not perform up to its expected standards, the faulty action and the way it violates the expected norms of conduct, are pointed out by the leader with contributions from team members. The whole idea of this recurrent exercise, as we see in this case, is not to assign responsibility to or blame any individual team member. Rather, accountable conduct is re-established and 
the alignment of team performance is emphasised as a shared practice in this discursive meta-activity.

\subsection{Concluding remarks}

In this article we have scrutinized the ways in which documentation in a knowledge management system is remediated for learning purposes in a specifically arranged activity. In the Case studio, the cases are used as documentation of the performed quality of work and, when unsuccessful, possible reasons are scrutinized and negotiated by the team, not so much to assess what has been achieved or not, but more to point to the expected quality of the team's work. The documentation of a case is accordingly not used to merely convey faults or exceptionally good performances. Instead of being used only as a form of assessment or accountability procedure in retrospect, the documentation allows for past events to be revisited and re-used as an example of something to learn and something to improve or strive for in the ongoing flow of daily activities. So what are the affordances of this particular kind of documentation and what kind of semiotic remediation is conducive in this discursive meta-activity?

What is characteristic in the Case studio is that the work-situated nature of the examples is salient and important for grounding more general formulations of norms, strategies and work procedures. In the discursive meta-activity, the case documentation is no longer drawn on as a document of work-in-progress. Rather it is used to display a gap between the performed and the expected, which calls for consideration. The difference between reading the case documentation as an everyday tool for remembering and pursuing work on the one hand, and as a tool for displaying 
what is expected in pursuing this work on the other, is made salient as a space for improvement. The materiality of the documentary practice as concretely grounded in the team's work (i.e. produced one text entry at a time) is here being re-used as a resource for the leader's narration which follows the same structure uncovering entry by entry. This seems to be important for the participants' apprehension of 'what happened' and it allows them to see the relevance of the case. As a tool for remediation, the documentary practice is thus re-visited as a way to reproduce and make sense of what is to be learned in situ. The leader's way of replicating the text's original construction places the participants in a simulated situation causing them to reflect upon the case progress step by step as if they were themselves to continue the case.

The case documentation - saved and re-used in the meta-activity - accordingly constitutes a material resource with certain affordances. It preserves daily communication and documentation of sequenced actions from the course of pursuing particular cases. Its materiality is non-transitory and as such it affords situated learning potential as an explicit mediational means. As a record of earlier action in the written form it allows for the participants to detach themselves from ongoing work. Documented actions can be followed chronologically, one can stop at certain points, and the sequenced information can be reviewed again and again in detail. As was touched upon by Hutchins (1995), representational tools, such as the case documentation in the present example, partake in action as they offer possibilities of saving and controlling essential information of the activity system. The capturing of this 'representational state' of things allows for "consistency checks" (Hutchins, 1995, p. 277) and becomes a potential resource for re-organizing future activities as 
noted also by Brown et al (2001). Organizational remembering captured through such material-semiotic tools makes it possible to check and re-check performed activities and logged information. The representational state of such tools implies that information is saved in ways that mirror the organizational structure; the local practices thus become visible and can be used for multiple purposes. In relation to this it is important to acknowledge that saved information is not to be seen as selfcontained but rather that the situated meaning has to be enacted, or 'read out of' the system in which they were saved. This is what Button and Sharrock (2000) showed when discussing how saved and retrieved information from a system needed to be collaboratively discussed to find the trouble source. Troubleshooting, in their case based on a fault report, was made possible by participants' reconstruction of previous events. Like in our own example, the software engineers could, with the textual representation as a basis, reconstruct information in such a way that it was possible to locate the problem.

However, in our empirical case the leader, who knows how the case evolves, plays a crucial role in signalling what to attend to. In that way, one can say that the leader advances the meaning affordances of the occasion by enacting and dramatizing the documentary resource. The leader is careful to show she is aiming at making certain points. Framing the documented past as enacted in the present situation parallels Orr's (1996) observation of story-telling as a forceful means to share knowledge and experience. As a dramatized and staged activity the engineers in the Case studio are invited to contribute at particular instances in the narrated sequences of events. These points seem to be made at the very instances where the concerns and considerations of performed actions need to be elaborated and critically reviewed. The modelling 
capacity of narratives thus provide possibilities for the engineers to learn about themselves and the organization from an inside-out perspective.

Neither training nor knowledge management systems alone can predict the kind of problems support engineers must be able to solve. The service community has had to evolve techniques for coping with new and unanticipated problems and preserving solutions for dissemination within the organizations. The situated nature of information technology systems and software/hardware usually calls for locally produced solutions and learning strategies. Informal learning, through overhearing, sharing of activities and maybe even in the construction of the shifts, are important day-to-day occasions for dissemination of knowledge. Discursive meta-activities, like the one we have studied, afford possibilities for illuminating in detail how members of an organization interpret and value previously performed actions. Situated understanding, as an element of successful help desk support, is thus tightly connected to in-service training. Institutionalised, yet locally arranged learning activities, offer opportunities for systematic dissemination of knowledge, negotiation of work routines and collective norm modelling through remediation of documentary practices. Learning work and norms of conduct from hypothetical cases does not offer the same opportunities for collective sense-making in terms of situated accountability constraints. In the Case studio, attention is paid to problems and dilemmas that are central to the employees in the workplace through the use of local documentation, creating a direct link with the everyday work that is going on just a few rooms away.

\section{Acknowledgements}


We would like to thank the anonymous reviewers for thoughtful and precise comments and suggestions. This research was conducted within The Linnaeus centre for research on learning, interaction and mediated communication in contemporary society (LinCS), and we also thank our colleagues for constructive criticism and support.

\section{References}

Ackerman, M. S., \& Halverson, C. (2004). Organizational memory as objects, processes, and trajectories: An examination of organizational memory in use. Computer Supported Cooperative Work (CSCW), 13(2), 155-189.

Brown, S., Middleton, D., \& Lightfoot, G. (2001). Performing the past in electronic archives: Interdependencies in the discursive and non-discursive ordering of institutional rememberings. Culture \& Psychology, 7(2), 123-144.

Button, G., \& Sharrock, W. (1998). The organizational accountability of technological work. Social Studies of Science, 28(1), 73-102.

Button, G., \& Sharrock, W. (2000). Design by problem-solving. In P. Luff, J. Hindmarsh \& C. Heath (Eds.), Workplace studies: Recovering work practice and informing system design (pp. 46-67). Cambridge, UK: Cambridge University Press.

Castellani, S., Grasso, A., O’Neill, J., \& Roulland, F. (2009). Designing technology as an embedded resource for troubleshooting. Computer Supported Cooperative Work (CSCW), 18(2), 199-227.

Castells, M. (1996). The rise of the network society (Vol. 1). Oxford: Blackwell. 
Chan, C. W., Chen, L.-L., \& Geng, L. (2000). Knowledge engineering for an intelligent case-based system for help desk operations. Expert Systems with Applications, 18(2), 125-132.

Das, A. (2003). Knowledge and productivity in technical support work. Management Science, 49(4), 416-431.

Davenport, T. H., \& Klahr, P. (1998). Managing customer support knowledge. California Management Review, 40(3), 195-208.

Eklund, A.-C., Mäkitalo, Å., \& Säljö, R. (2010). Noticing the past to manage the future: On the organization of shared knowing in IT-support practices. In S. Ludvigsen, A. Lund, I. Rasmussen \& R. Säljö (Eds.), Learning across sites. New tools, Infrastructures and Practices. London: Routledge.

El Sawy, O. A., \& Bowles, G. (1997). Redesigning the customer support process for the electronic economy: Insights from storage dimensions. MIS Quarterly, 21(4), 457-483.

González, L. M., Giachetti, R. E., \& Ramirez, G. (2005). Knowledge managementcentric help desk: specification and performance evaluation. Decision Support Systems, 40, 389-405.

Gray, P. H. (2001). A problem-solving perspective on knowledge management practices. Decision Support Systems, 31(1), 87-102.

Gray, P. H., \& Durcikova, A. (2006). The role of knowledge repositories in technical support environments: Speed versus learning in user performance. Journal of Management Information Systems, 22(3), 159-190.

Halverson, C. A., Erickson, T., \& Ackerman, M. S. (2004). Behind the help desk: Evolution of a knowledge management system in a large organization. Paper presented at the CSCW'04, Chicago, IL, USA. 
Heras, S., García-Pardo, J. Á., Ramos-Garijo, R., Palomares, A., Botti, V., Rebollo, M., \& Julián, V. (2009). Multi-domain case-based module for customer support. Expert Systems with Applications, 36(3), 6866-6873.

Hutchins, E. (1995). How a cockpit remember its speed. Cognitive Science, 19, 256288.

Kajko-Mattsson, M. (2003). Infrastructures of virtual IT enterprises. Paper presented at the International Conference on Software Maintenance (ICSM'03), Amsterdam, The Netherlands.

Leung, N., \& Lau, S. (2006). Relieving the overloaded help desk: A knowledge management approach. Communications of International Information Management Association, 6(2), 87-98.

Leung, N., \& Lau, S. (2007). Information technology help desk survey: To identify the classification of simple and routine enquiries. Journal of Computer Information Systems, 47(4), 70-81.

Linell, P. (2009). Rethinking language, mind, and world dialogically: Interactional and contextual theories of human sense-making. Charlotte, NC: Information Age Publ.

Marcella, R., \& Middleton, I. (1996). The role of the help desk in the strategic management of information systems. OCLC Systems \& Services, 12(4), 4-19.

McBride, N. (2009). Exploring service issues within the IT organisation: Four minicase studies. International Journal of Information Management, 29(3), 237-243.

Mäkitalo, A. (2012). Professional learning and the materiality of social practice. Journal of Education and Work, 25(01), 59-78. 
Orlikowski, W. J., \& Yates, J. (1994). Genre repertoire: The structuring of communicative practices in organizations. Administrative Science Quarterly, $39,541-574$.

Orr, J. E. (1996). Talking about machines: An ethnography of a modern job. Ithaca, NY: ILR Press.

Prior, P., Hengst, J., Roozen, K., \& Shipka, J. (2006). 'I'll be the sun': From reported speech to semiotic remediation practices. Text \& Talk, 26(6), 733-766.

Quayle, M., \& Durrheim, K. (2006). When the chips are down: Social and technical aspects of computer failure and repair. Interacting with Computers, 18(6), 12601277.

Ryan, M.-L. (2006). Avatars of story. Minneapolis, MN: University of Minnesota Press.

Scheeres, H. (2007). Talk and texts at work: Beyond language and literacy skills. Literacy \& Numeracy Studies, 15(2), 5-18.

Schegloff, E. (2005). On Complainability. Social Problems, 52(4), 449-476.

Simoudis, E. (1992). Using case-based retrieval for customer technical support. IEEE Expert, 7(5), 7-12.

Spence, P. R., \& Reddy, M. (2012). Beyond expertise seeking: A field study of the informal knowledge practices of healthcare IT teams. Computer Supported Cooperative Work (CSCW), 21(2-3), 283-315.

Säljö, R. (2010). Digital tools and challenges to institutional traditions of learning: technologies, social memory and the performative nature of learning. Journal of Computer Assisted Learning, 26(1), 53-64. 
Säljö, R. (2012). Literacy, digital literacy and epistemic practices: The co-evolution of hybrid minds and external memory systems. Nordic Journal of Digital Literacy, 12(1), 5-20.

Vygotsky, L. S. (1997). The Instrumental Method in Psychology. In R. Reiber \& J. Wollock (Eds.), The Collected Works of L.S. Vygotsky; Volume 3 Problems of the theory and history of psychology (pp. 85-89). London: Plenum Press.

Wertsch, J. V. (1998). Mind as action. New York: Oxford University Press.

\section{Appendix}

\section{Transcript legend}




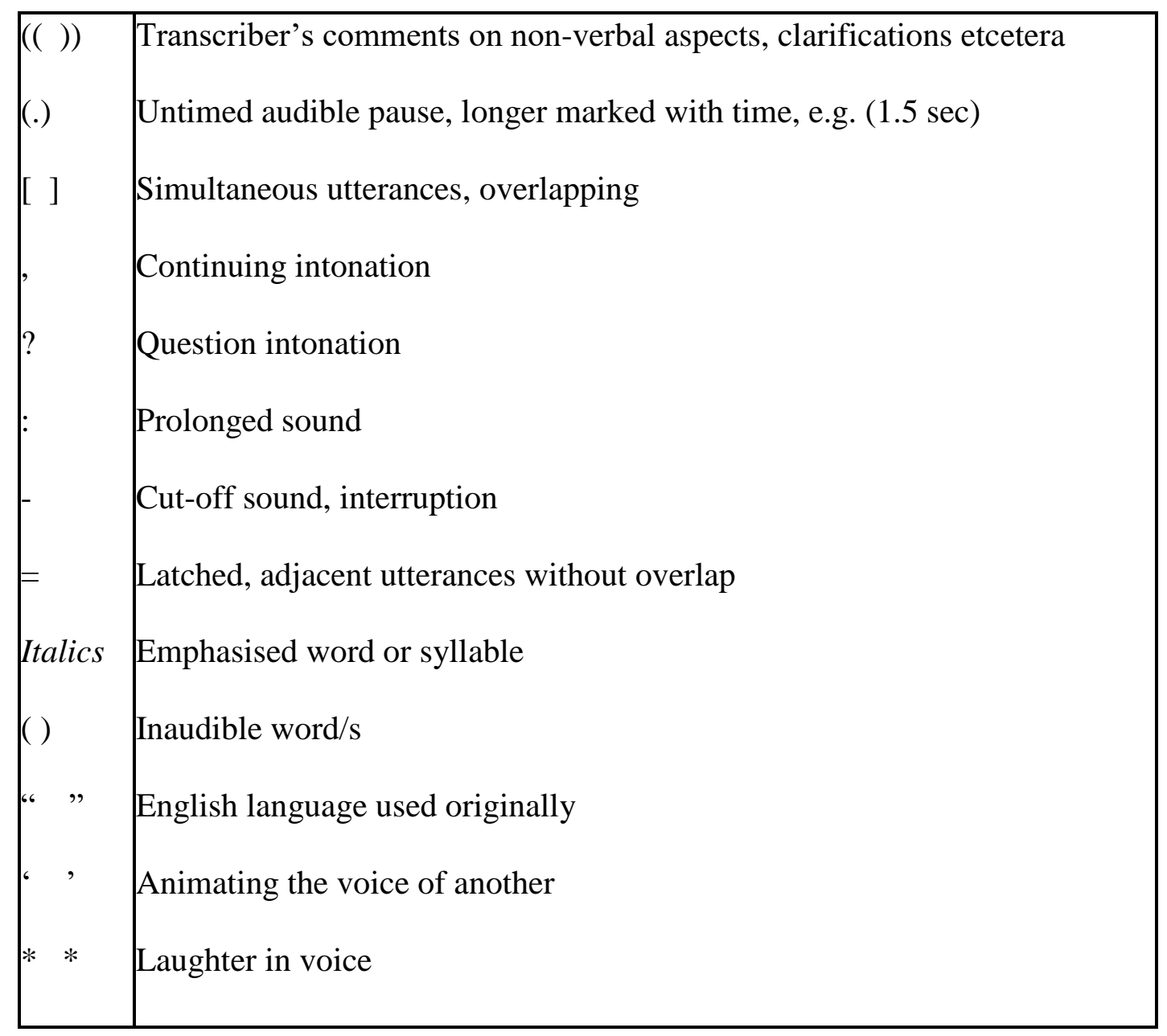

